\title{
Corrigendum: Tiny RNAs associated with transcription start sites in animals
}

Ryan J Taft, Evgeny A Glazov, Nicole Cloonan, Cas Simons, Stuart Stephen, Geoffrey J Faulkner, Timo Lassmann, Alistair R R Forrest, Sean M Grimmond, Kate Schroder, Katharine Irvine, Takahiro Arakawa, Mari Nakamura, Atsutaka Kubosaki, Kengo Hayashida, Chika Kawazu, Mitsuyoshi Murata, Hiromi Nishiyori, Shiro Fukuda, Jun Kawai, Carsten O Daub, David A Hume, Harukazu Suzuki, Valerio Orlando, Piero Carninci, Yoshihide Hayashizaki \& John S Mattick

Nat. Genet. 41, 572-578 (2009); published online 19 April 2009; corrected after print 26 June 2009

In the version of this article initially published, some author affiliations were incorrectly stated. The error has been corrected in the HTML and PDF versions of the article.

\section{Erratum: Narcolepsy is strongly associated with the T-cell receptor alpha locus}

Joachim Hallmayer, Juliette Faraco, Ling Lin, Stephanie Hesselson, Juliane Winkelmann, Minae Kawashima, Geert Mayer, Giuseppe Plazzi, Sona Nevsimalova, Patrice Bourgin, Sheng Seung-Chul Hong, Yutaka Honda, Makoto Honda, Birgit Högl, William T Longstreth Jr, Jacques Montplaisir, David Kemlink, Mali Einen, Justin Chen, Stacy L Musone, Matthew Akana, Taku Miyagawa, Jubao Duan, Alex Desautels, Christine Erhardt, Per Egil Hesla, Francesca Poli, Birgit Frauscher, Jong-Hyun Jeong, Sung-Pil Lee, Thanh G N Ton, Mark Kvale, Libor Kolesar, Marie Dobrovolná, Gerald T Nepom, Dan Salomon, H-Erich Wichmann, Guy A Rouleau, Christian Gieger, Douglas F Levinson, Pablo V Gejman, Thomas Meitinger, Terry Young, Paul Peppard, Katsushi Tokunaga, Pui-Yan Kwok, Neil Risch \& Emmanuel Mignot

Nat. Genet. 41, 708-711 (2009); published online 3 May 2009; corrected after print 26 June 2009

In the version of this article initially published, Seung-Chul Hong was incorrectly listed as Sheng Seung-Chul Hong. The error has been corrected in the HTML and PDF versions of the article. 